AperTO - Archivio Istituzionale Open Access dell'Università di Torino

\title{
An ontological perspective on thematic roles
}

\section{This is the author's manuscript}

Original Citation:

\section{Availability:}

This version is available http://hdl.handle.net/2318/1637585

since 2018-09-03T15:56:25Z

Publisher:

Springer International Publishing

Published version:

DOI:10.1007/978-3-319-58694-6

Terms of use:

Open Access

Anyone can freely access the full text of works made available as "Open Access". Works made available under a Creative Commons license can be used according to the terms and conditions of said license. Use of all other works requires consent of the right holder (author or publisher) if not exempted from copyright protection by the applicable law. 


\title{
An ontological perspective on thematic roles*
}

\author{
Anna Goy ${ }^{1}$, Diego Magro ${ }^{1}$, Marco Rovera ${ }^{1}$ \\ ${ }^{1}$ Dipartimento di Informatica, Università di Torino, Torino, Italy \\ \{annamaria.goy, diego.magro, marco.rovera\}@unito.it
}

\begin{abstract}
We face the issue of formally modeling roles in the semantic representation of events: we propose a distinction between thematic roles and social roles, and we show that they have important ontological differences, suggesting distinct formal representations. We apply our approach in the context of the Harlock'900 project, including the definition of thematic roles as binary properties in the HERO ontology.
\end{abstract}

Keywords: Ontological analysis · Event ontology · Thematic Roles · Ontology design patterns

\section{Introduction}

In the Semantic Web and ontology modeling community, the representation of roles has being always considered an important challenge. However, when discussing this issue within different specific fields, the notion of role has been interpreted in many, different, and sometimes confusing ways. In this paper we face the issue of formally modeling roles in the perspective of the ontological representation of events: we briefly mention the most relevant related work (Section 2), we discuss our ontological analysis, and we propose a formal representation for thematic roles (Section 3). We conclude by summarizing the main future directions of our work (Section 4).

\section{Related Work and Background}

In this section, we briefly sketch the modeling choices concerning roles that can be found in some well-known (event) ontologies, and an (incomplete) outline of the extremely wide literature about thematic roles in the (computational) linguistics field.

None of the analyzed ontologies provides a fine-grained account of the different ways in which entities can participate in events. However, all of them provide some means to represent general participation (e.g., EDM [1] among many others), and some of them also offer a pattern for representing roles that can be used to express

\footnotetext{
* POSTPRINT VERSION. Cite as: A. Goy, D. Magro, M. Rovera. An ontological perspective on thematic roles. In P. Ciancarini, F. Poggi, M. Horridge, J. Zhao, T. Groza, M.C. SuarezFigueroa, M. d'Aquin, V. Presutti (Eds.), Knowledge Engineering and Knowledge Management, LNAI 10180, pp. 123-126, Springer, 2017. DOI 10.1007/978-3-319-58694-6
} 
specific modalities of event participation in conjunction with external resources (e.g., SEM [15], CIDOC-CRM [5], Event Model F [14]). Moreover, none of the analyzed ontologies make any (formal) distinction between roles played by event participants and social roles (see Section 3).

In the perspective taken in this paper, undoubtedly influential works in the (computational) linguistic area are those by Pustejovsky [12], Jackendoff [4], and Levin and Rappaport [6], claiming that thematic roles are not semantic primitives, but relations between individuals and events, possibly emerging from rich semantic structures. Another significant thread is Frame Semantics, introduced by Fillmore [2], and representing the starting point of the FrameNet project (framenet.icsi.berkeley.edu), a huge English lexical database, where word meanings correspond to frames, representing event types, and including participants playing different roles. Finally, an important debate concerns thematic roles specificity: are thematic roles specific for every type of event (buyer, seller, ...) [10], or are they general ways of participating in events of different kinds (agent, patient, ...) [3, 6]?

\section{An Ontological Approach to Thematic Roles}

Our analysis of the literature and ontological models led us to identify at least two different notions that have been called "roles", but show a quite different nature:

- The role somebody/something plays when (s)he/it participates in an event ("Brutus killed Caesar with a knife", where Brutus plays the role of killer/agent, Caesar that of killed/patient, and the knife plays the role of instrument) - sense (a).

- The role somebody plays within a given social context ("Renzi is the current Italian Prime Minister", where no event is explicitly mentioned, but there is clearly somebody who plays a role, that of Italian Prime Minister) - sense (b).

Obviously, these different senses of the notion of role are not totally independent; for example, if somebody kills someone (sense (a)), it can be socially considered a killer (sense (b)); or somebody can participate in an international meeting (sense (a)) "qua" Italian Prime Minister (sense (b)). However, we will show that:

1. Besides similarity, sense (a) and (b) show important ontological differences.

2. As a consequence, they should be modeled in different ways and roles in sense (a) can be modeled as binary properties, connecting the event to its participants.

Following Masolo and colleagues [9], we characterize roles as anti-rigid and founded concepts. Roles (both social and thematic ones) are anti-rigid [16] since any individual that plays a role does not play it necessarily. Anti-rigidity also implies that any entity can start and stop playing a role, or it can change role during its life: e.g., no Prime Minister necessarily is a Prime Minister, and any Prime Minister starts and stops being a Prime Minister at a given time in her/his life. Similarly, no patient in an event necessarily is a patient, (s)he/it stops being a patient when the event ends and there can be time periods during which (s)he/it is not patient in any event. Moreover, in general, an entity can play the same (social or thematic) role several times, a (social 
or thematic) role can be played by different entities at the same time and an entity can play different roles simultaneously. Moreover, (social) roles are founded concepts [9]: intuitively, a concept $x$ is founded if and only if its definition mentions another concept $y$, "such that for each entity classified by $x$, there is an entity classified by $y$ which is external to it" ${ }^{1}$ [9]. It is easy to see that foundedness holds also for thematic roles, since any definition of a thematic role necessarily mention the notion of event (e.g., the beneficiary role is typically defined as "the entity taking advantage of an event") and each particular event is external to any entity that can play a thematic role in it. As a consequence, both thematic and social roles are roles in the sense formalized by Masolo and colleagues [9], but social roles cannot be equated with the roles played when participating in an event: in fact, if somebody is a musician (social role), (s)he is still a musician also when sleeping (i.e., when (s)he is not participating in any event in which (s)he acts as a musician) [7]. The distinction between thematic and social roles can be further supported by considering the relation between an event and its participants which is bounded by the temporal boundaries of the event itself (if I participate in a hitting event as a patient, I stop being a patient when the event ends).

The ontological differences between thematic roles (sense (a)) and social roles (sense (b)) underpin our claim that they should be formalized in different ways. In computational ontologies, roles are usually reified and placed in the domain of discourse, in order to offer models that enable one to "talk about roles" and to explicitly represent relations they are involved in. Moreover, sometimes, also role attributions (i.e. the relationships between entities and the roles they play) are reified, usually in order to be able to assign temporal boundaries to the relation between an entity and the (social) role it plays (see, for instance, the Publishing Role Ontology [11]). Our hypothesis is that the formal representation of events requires a model that allows us to use social and thematic roles, and to talk about social roles, while we do not need to talk about thematic roles. In particular, we do not need the role attribution pattern mentioned above for thematic roles, since the events themselves already provide the spatio-temporal context required; therefore, while social roles should be conveniently reified, we do not need to reify thematic roles. We think that the nature of thematic roles is better formally accounted for by means of binary properties, providing a more immediate representation of the close relationships between events and participants.

In order to verify our hypothesis, we applied our approach in the specific context of Harlock'900 [3, 13], a project (2016-2018) involving the Computer Science Dept. of the University of Torino and the Fondaz. Ist. Piemontese A. Gramsci, a member of the Polo del '900 (www.polodel900.it). Within Harlock'900, we are developing HERO, an Historical Event Representation Ontology relying on DOLCE [8]. As an example, we show here the axioms defining the generic notion of participation in an event and the "classical" patient role (free variables are universally quantified):

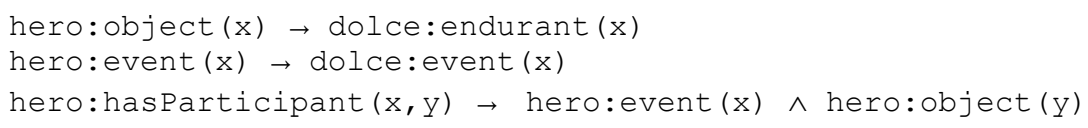

1 "Externality" is actually a complex notion that, in many practical cases, can be conveniently approximated by stating that $y$ is external to $x$ iff $x$ is not part of $y$ and $y$ is not part of $x$. 


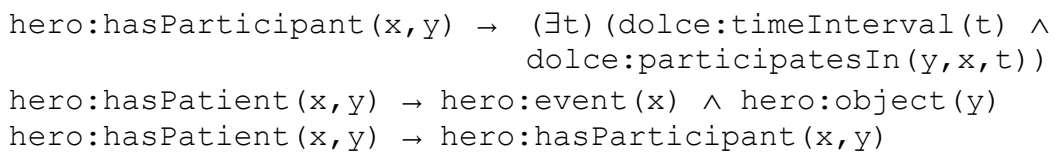

\section{$4 \quad$ Conclusions and Future Work}

In this paper, we provided an ontological analysis of the notions of social and thematic role, arguing for the suitability of representing thematic roles as properties connecting events and their participants. Obviously, a lot of work can start from here. For example, the issues about general versus specific thematic roles should be taken into account. We are also building an OWL version of the HERO ontology, to be used to test our approach. Finally, another related notion deserves further investigation: the role attribution expressing a point of view ("The liberators landed at Sicily", where the Anglo-American allies are seen as liberators, from a specific historical perspective).

\section{References}

1. EDM: EDM Definition of the Europeana Data Model v.5.2.7, pro.europeana.eu (2016)

2. Fillmore, C. J.: Frame semantics. In: The Linguistic Society of Korea (ed.). Linguistics in the Morning Calm. pp. 111-137, Hanshin, Soeul (1982)

3. Goy, A., Magro, D., Rovera, M. Ontologies and historical archives: A way to tell new storie. Applied Ontology, 10(3-4), 331-338 (2015)

4. Jackendoff, R.: Semantic structures. MIT Press, Cambridge, MA (1990)

5. Le Boeuf, P., Doerr, M., Ore, C.E., Stead, S. (eds.): Definition of the CIDOC Conceptual Reference Model, v. 6.2.1. ICOM/CIDOC CRM SIG (2015)

6. Levin, B., Rappaport, M.. Wiping the slate clean: a lexical semantic exploration. In: Levin, B., Pinker, S. (eds.) Lexical and conceptual semantics. pp.123-151, Blackwell, Cambridge, MA (1991)

7. Loebe, F.: An analysis of roles. Toward ontology-based modelling. Master's Thesis, University of Leipzig (2003)

8. Masolo, C., Borgo, S., Gangemi, A., Guarino, N., Oltramari, A.: WonderWeb Deliverable D18. Technical Report, CNR (2003)

9. Masolo, C., Vieu, L., Bottazzi, E., Catenacci, C., Ferrario, R., Gangemi, A., Guarino, N.: Social Roles and Their Descriptions. In: Dubois, et al. (eds.) Proc. KR2004. pp. 267-277. AAAI Press, CA (2004)

10. McRae, K., Ferretti, T. R., Amyote, L.: Thematic roles as verb-specific concepts. Language and Cognitive Processes, 12(2/3), 137-176 (1997)

11. Peroni, S., Shotton, D., Vitali, F.: Scholarly Publishing and the Linked Data: Describing Roles, Statuses, Temporal and Contextual Extents. In: Sack H., Pellegrini, T. (eds.) Proc. iSemantics 2012. pp. 9-16. ACM, New York, NY (2012)

12. Pustejovsky, J.: The Syntax of Event Structure. Cognition, 41(1-3), 47-81 (1991)

13. Rovera, M.: A Knowledge-Based Framework for Events Representation and Reuse from Historical Archives. In: Sack, et al. (eds.) The Semantic Web - Proc. ESWC 2016. LNCS 9678, pp. 845-852, Springer, Heidelberg (2016) 
14. Scherp, A., Franz, T., Saathoff, C., Staab, F.: F - A Model of Events based on the Foundational Ontology DOLCE+DnS Ultralite. In: Gil Y., Noy, N. (eds) Proc. K-CAP 2009. pp. 137-144, ACM, New York (2009)

15. van Hage, W.R., Malaisé, V., Segers, R., Hollink, L., Schreiber, G.: Design and Use of the Simple Event Model (SEM). Journal of Web Semantics, 9, 128-136 (2011)

16. Welty, C., Guarino, N.: Supporting Ontological Analysis of Taxonomic Relationships. Data and Knowledge Engineering, 39, 51-74 (2001) 